\title{
Rehabilitation of Right Posterior Maxillary Arch with Tilted Implant Placement to Bypass Maxillary Sinus with Help of Implant Supported Fixed Prosthesis: A Case Report
}

\author{
Dr. Priyesh Kesharwani MDS $^{1 *}$, Dr. Balaji V², Dr Jabir K ${ }^{3}$, Dr. Rishabh Bhanot ${ }^{4}$, Dr Navneet Kaur ${ }^{5}$, Dr. V K Sasank \\ Kuntamukkula MDS $^{6}$ \\ ${ }^{1}$ Oral and Maxillofacial Surgeon, Consultant and Private Practitioner DENT-O-FACIAL Multispeciality Clinic, Mira road, Thane-Mumbai India \\ ${ }^{2}$ Sr. Asst. Professor, Department of Dental Surgery, Govt. Viluppuram Medical College \& Hospital, Tamil Nadu India \\ ${ }^{3}$ Post graduate, OMFS, Mes Dental College, Malappuram, Kerala India \\ ${ }^{4}$ Consultant Oral and Maxillofacial Surgeon, SRCJC Hospital, Ludhiana Punjab India \\ ${ }^{5}$ Reader, Department of oral and maxillofacial surgery, Guru Nanak Dev Dental College \& RI, Sunam, Punjab India \\ ${ }^{6}$ Assistant Professor, Department of Oral and Maxillofacial Surgery, Sri Sai College of Dental Surgery, Vikarabad, India
}

\author{
DOI: $10.36348 /$ sjodr.2019.v04i11.002 \\ | Received: 02.11.2019 | Accepted: 11.11.2019 | Published: 15.11.2019
}

*Corresponding author: Dr. Priyesh Kesharwani MDS

\section{Abstract}

The early loss of maxillary posterior teeth leads to maxillary sinus pneumatisation, reducing the alveolar ridge height, and thus posing challenge for implant placement. Owing to mechanical and anatomic difficulties, implant treatment in the atrophic maxilla represents a cumbersome task. The maxillary sinus floor augmentation procedure is still not universally accepted because of its complexity and its unpredictability. This condition may be treated with an elevation of the maxillary sinus floor, which is usually accomplished by lateral or transcrestal approach to the antrum. As an alternative to these augmentation procedures, a more conservative treatment option would be to either place short implants or to bypass the sinus floor. This case report emphasizes on maxillary sinus by pass with tilted implants in close proximity to the sinus wall, thus, avoiding sinus floor elevation \& bone grafting procedures.

Keywords: Rehabilitation, Tilted Implants, Maxillary Sinus.

Copyright @ 2019: This is an open-access article distributed under the terms of the Creative Commons Attribution license which permits unrestricted use, distribution, and reproduction in any medium for non-commercial use (NonCommercial, or CC-BY-NC) provided the original author and source are credited.

\section{INTRODUCTION}

Replacement of lost teeth with dental implants has been used for replacing missing teeth for more than five decades and considered as a feasible treatment modality to replace missing teeth. Dental Implants were first introduced by "Per-Ingvar Branemark" where he observed that human body would not only tolerate titanium but also integrate into living bone tissues [1].

The early loss of maxillary posterior teeth leads to maxillary sinus pneumatisation, reducing the alveolar ridge height, and thus posing challenge for implant placement [2]. Recently, dental implant supported prostheses (implant overdentures) have offered many advantages such as improved retention and support, better speech, and enhanced mastication ability when compared to the conventional methods [35]. It is considered as cheaper option but they may require more involved maintenance, thus rendering removable treatment not as economical as it may appear [6].
Pneumatisation of the maxillary sinus reduces the available amount of bone in both width and height for the placement of dental implants in the edentulous posterior maxilla.

Next problem that may crop up in this area is that of the quality of the bone, that is frequently less dense, more medullar and thinner than in the jaw [7-9].

This condition may be treated with an elevation of the maxillary sinus floor, which is usually accomplished via either a lateral (so-called CaldwellLuc approach) or a transcrestal approach to the antrum.

Elevation of the maxillary sinus floor was first reported by Boyne and James as a preparation for the placement of blade implants (10). This first technique involves a quite complex surgery, especially if an autogenous graft is considered necessary. Ellegaard et al. and Lundgren et al. presented later techniques without grafts $[11,12]$. 
Later a less invasive procedure for sinus floor elevation, with immediate implant placement, was introduced by summers in 1994 [13-15]. The Schneiderian membrane and the bony floor of the sinus are elevated with osteotomes from a crestal approach, without the preparation of a lateral window. At the same time, some kind of graft may be placed $[14,16]$.

As alternative to these augmentation procedures, a more conservative treatment option to overcome the inadequate bone quantity would be to place short implants to avoid entering the sinus cavity. On the other hand, for the placement of even short implants, there is still requiring for at least $6 \mathrm{~mm}$ of residual bone height [17].

In this present case report we faced above mentioned problems of sinus pneumatisation due to aging and alveolar ridge resorbtion. To avoid any sinus related complication and to achieve good stability for implant attempt was made to place tilted implant angulated in maxillary tubrosity to for proper stability and anchorage.

\section{CASE REPORT}

A patient reported to the clinic with a complaint of edentulous posterior maxilla in relation to 14. General patient evaluation was carried out to rule out any medical history of diabetes or bone related disorders. The presurgical examinations were done for the patient included a panoramic radiograph. The extension of the maxillary sinus and the volume and density of the remaining bone was evaluated by means of maxillary computed tomography. The bone quantity and quality were estimated based on the presurgical radiography and on the resistance to surgical drilling during surgery and classified according to the index described by Lekholm and Zarb [18].

Pharmacological protocol: antimicrobial prophylaxis was administered to the patient with amoxycillin $850 \mathrm{mg}+$ clavulanic acid $125 \mathrm{mg}$ every $8 \mathrm{~h}$ for 7 days, starting from 3 hours before the operation. After an initial rinse with chlorhexidine digluconate $0.2 \%$, for 1 minute to disinfect the mouth, loco-regional anesthesia was performed with lignocaine hydrochloride $2 \%$ with epinephrine 1:100,000.

The surgery was initiated by a mid-crestal incision in keratinized gingiva starting from 2nd premolar region to $2^{\text {nd }}$ molar region side in maxilla and a mucoperiosteal flap was elevated exposing the vestibular bone wall. The posterior implant was tilted distally at about a 30-degree angle and placed parallel to the anterior wall of the maxillary sinus, with the following measures: $4.2 \times 12 \mathrm{~mm}$ and the 4 anterior implants $(4.2 \mathrm{~mm} \times 12 \mathrm{~mm})$ were placed in a vertical position (Figure 1, 2, 3 and 4). After component installation, a $30 \mathrm{~N} / \mathrm{cm}$ torque was applied following manufacturer's instructions. Sinus bypass was achieved successfully by angulating posterior implant. The flap was closed using monofilament non-absorbable polyamide surgical suture 4-0. One week after surgery, sutures were removed, and patient was controlled monthly in follow-up appointments to both assess the soft tissue health and to adjust the provisional prosthesis.

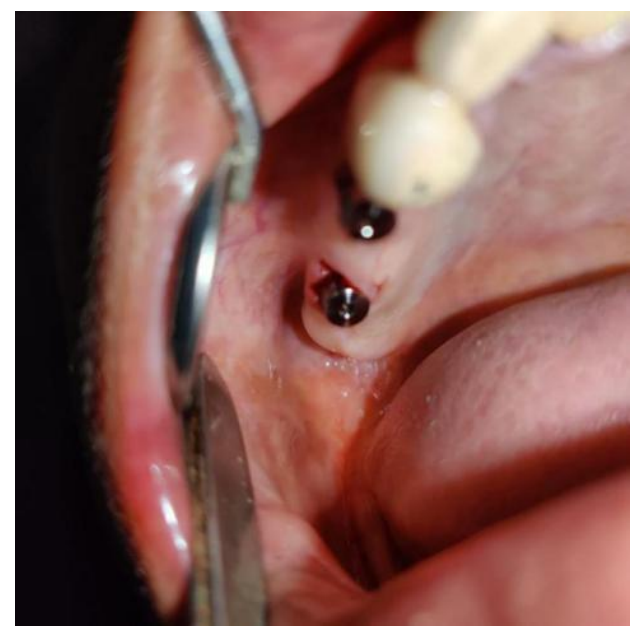

Fig-1: Implant placed in 15 and 17 region

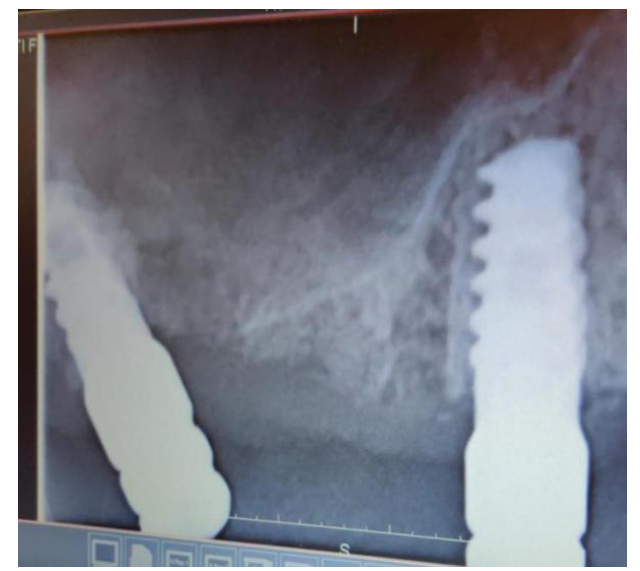

Fig-2: Radiograph showing tilted implant in 27 and straight implant in 15

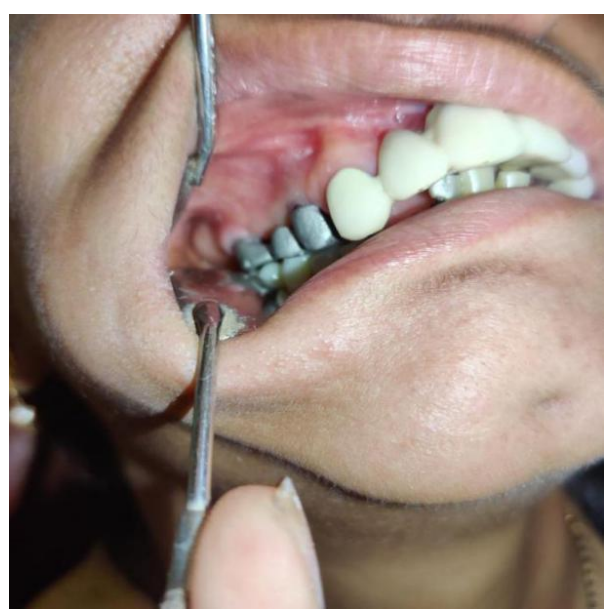

Fig-3: Temporary prosthesis tryin on placed implant 
Priyesh Kesharwani et al; Saudi J Oral Dent Res, Nov 2019; 4(11): 763-766

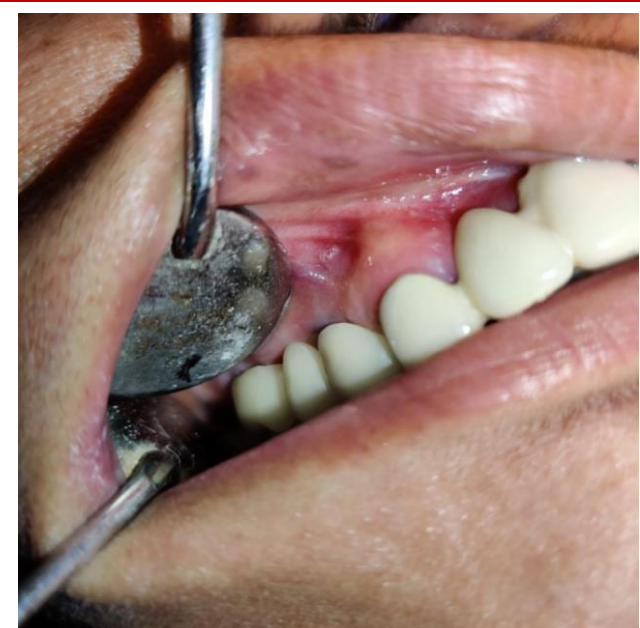

Fig-4: Final prosthesis placement

\section{DISCUSSION}

In case of atrophic maxilla, implant placement isn't possible without undergoing invasive procedures like bone augmentation or sinus lift procedure or both. Several types of complications may occur during and after the sinus elevation procedure like Schneiderian membrane perforation, nose bleeding, post-operative pain and swelling even though it was not described an important negative effect on implant success rates [19]. But patient may be under psychological stress and addition of burden of an extra surgery and increased cost if enough bone isn't available to carry out sinus lift and implant placement at same appointment [20].

Bone grafting, though practicable now a days is dependent on many factors like type of bone graft used (autogenous, alloplastic or xenograft), host response, age of patient, various complications associated with grafting procedure, infection and most importantly time spent while graft material matures and is taken up by bone. One review revealed that there are not many studies providing data on success rate of dental implants placed in onlay graft augmented ridges and demonstrated, on average, a poor methodological quality [21].

Considering all these things, placement of an angulated implant avoiding both invasive procedures like sinus lift and bone augmentation procedure is a viable treatment option [22].

Tilted implants were useful in the treatment of edentulous jaws avoiding the bone augmentation procedures and the involvement of anatomical structures during surgery. However, tilting of distal implants in full-arch rehabilitation allows to reduce cantilever length and to augment the antero-posterior distance between the most anterior implant emergence and the most posterior ones with several prosthetic advantages [23].
Surgical complications during implant placement in posterior region such as bone resorption, poor bone quality, jaw shape, location of mental foramen or loop of alveolar nerve, presence of sinus, mandibular nerve and canal associated with maxilla and mandible can be taken care of [24].

\section{Rationale of tilted implants}

- To achieve primary implant stability (35 to $45 \mathrm{Ncm}$ inser tion torque) [25].

- Indicated with a minimum bone width of $5 \mathrm{~mm}$ and mini mum bone height of $10 \mathrm{~mm}$ from canine to canine in max illa and $8 \mathrm{~mm}$ in mandible.

- If angulation is $30^{\circ}$ or more, the tilted implants can be splinted.

- $\quad$ For tilted posterior implants, the distal screw access holes should be located at the occlusal face of the first molar, the second premolar, or the first premolar.

- Improved masticatory functions in terms of chewing ef ficiency and bite force [24].

\section{Disadvantage of tilted implants}

- Technique sensitive procedure.

- Surgeon needs to be very skillful.

- Computer guided surgical stent required for implant to be placed in desired angulation.

- Not even slight change in angulation can be done.

- Long term studies are not available [26].

Various studies carried out regarding success rate of angulated implants have shown same or less amount of crestal bone loss in comparison to axial implants $[10,14,19]$. Some studies have advocated that we should not place single angulated implant to replace single missing tooth since prosthesis fabricated over it will be of fixed type creating more amount and duration of load and increased off axis loading [25].

Therefore, long term clinical and histopathological studies are necessary and recommended to utilise this modality in routine practise. However, this procedure is a viable concept in short and medium term.

\section{CONCLUSION}

This technique is extremely technique sensitive, useful in patients with resorbed ridges but long term studies are required to evaluate its success rate in terms of load distribution, marginal bone loss around implant and prosthesis survival but currently many practitioners are treating patients with this modality with a great success.

\section{REFERENCES}

1. Branemark. (1989). "Tissue Integrated Prosthesis: Quintessence Books.

2. Malo, P., de Araújo Nobre, M., Lopes, A., Moss, S. M., \& Molina, G. J. (2011). A longitudinal study of 
the survival of All-on-4 implants in the mandible with up to 10 years of follow-up. The Journal of the American Dental Association, 142(3), 310-320.

3. Nag, P. V. R., Sarika, P., \& Khan, R. (2018). Tall and tilted pin hole immediately loaded implants (TTPHIL) technique for maxillary arch rehabilitation. International Journal of Research \& Review, 5, 104-10.

4. Thomason, J. M., Feine, J., Exley, C., Moynihan, P., Müller, F., Naert, I., ... \& Lynch, C. (2009). Mandibular two implant-supported overdentures as the first choice standard of care for edentulous patients-the York Consensus Statement. British dental journal, 207(4), 185.

5. Singh, A. V., Singh, S., \& Rojo, A. V. (2013). Quality life for elderly edentulous patients with implant over dentures, implantology section. Dental Practice, 22-25.

6. Duyck, J., Van Oosterwyck, H., Vander Sloten, J., De Cooman, M., Puers, R., \& Naert, I. (2000). Magnitude and distribution of occlusal forces on oral implants supporting fixed prostheses: an in vivo study. Clinical oral implants research, 11(5), 465-475.

7. Watzek, G., Weber, R., Bernhart, T., Ulm, C. H., \& Haas, R. (1998). Treatment of patients with extreme maxillary atrophy using sinus floor augmentation and implants: preliminary results. International journal of oral and maxillofacial surgery, 27(6), 428-434.

8. Ferrigno, N., Laureti, M., \& Fanali, S. (2006). Dental implants placement in conjunction with osteotome sinus floor elevation: a 12-year life-table analysis from a prospective study on 588 ITI® implants. Clinical oral implants research, 17(2), 194-205.

9. Guirado, J. L. C., Yuguero, R. S., \& Zamora, G. P. (2006). Compressive osteotomes for expansion and maxilla sinus floor lifting. Medicina oral, patología oral y cirugía bucal. Ed. inglesa, 11(1), 12.

10. BOYNE, P. J. (1980). Grafting of the maxillary sinus floor with autogenous marrow and bone. $J$. Oral Surg., 38, 613-616.

11. Ellegaard, B., Kølsen-petersen, J., \& Baelum, V. (1997). Implant therapy involving maxillary sinus lift in periodontally compromised patients. Clinical Oral Implants Research, 8(4), 305-315.

12. Summers, R. B. (1994). The osteotome technique: Part 2--The ridge expansion osteotomy (REO) procedure. Compendium (Newtown, Pa.), 15(4), 422-424.

13. Tatum, J. H. (1986). Maxillary and sinus implant reconstructions. Dental Clinics of North America, 30(2), 207-229.

14. Summers, R. B. (1994). A new concept in maxillary implant surgery: the osteotome technique. Compendium (Newtown, Pa.), 15(2), 152-154.

15. Fugazzotto, P. A. (2002). Immediate implant placement following a modified trephine/osteotome approach: success rates of 116 implants to 4 years in function. International Journal of Oral \& Maxillofacial Implants, 17(1).

16. Jensen, O. T., Shulman, L. B., Block, M. S., \& Iacono, V. J. (1998). Report of the sinus consensus conference of 1996. The International journal of oral \& maxillofacial implants, 13, 11-45.

17. Pjetursson, B.E., Lang, N.P.(2000). Sinus floor elevation utilizing the transalveolar approach. Periodontol, 2014;66: 59-71.

18. Lekholm, U., Zarb, G.A. (1985). Patient selection and preparation. In: Brinemark P-I, Zarb GA, Albrektsson T, eds. Tissue-integrated prostheses: osseointegration in clinical dentistry. Chicago: Quintessence, 199-209.

19. Taschieri, S., Del Fabbro, M., Tsesis, I., \& Corbella, S. (2012). Maxillary sinus in relation to modern oral and maxillofacial surgery. International journal of dentistry, 2012.

20. Bortoluzzi, M. C., Manfro, R., Fabris, V., Cecconello, R., \& Derech, E. D. A. (2014). Comparative study of immediately inserted dental implants in sinus lift: 24 months of followup. Annals of maxillofacial surgery, 4(1), 30.

21. Clementini, M., Morlupi, A., Agrestini, C., \& Ottria, L. (2011). Success rate of dental implants inserted in autologous bone graft regenerated areas: a systematic review. ORAL \& implantology, 4(3-4), 3.

22. Lim, T. J., Csillag, A., Irinakis, T., Nokiani, A., \& Wiebe, C. B. (2004). Intentional angulation of an implant to avoid a pneumatized maxillary sinus: a case report. Journal-Canadian Dental Association, 70(3), 164-169.

23. Krekmanov, L., Kahn, M., Rangert, B., \& Lindström, H. (2000). Tilting of posterior mandibular and maxillary implants for improved prosthesis support. International Journal of Oral \& Maxillofacial Implants, 15(3).

24. Taruna, M., Chittaranjan, B., Sudheer, N., Tella, S., \& Abusaad, M. (2014). Prosthodontic perspective to all-on-4® concept for dental implants. Journal of clinical and diagnostic research: JCDR, 8(10), ZE16.

25. Asawa, N., Bulbule, N., Kakade, D., \& Shah, R. (2015). Angulated implants: an alternative to bone augmentation and sinus lift procedure: systematic review. Journal of clinical and diagnostic research: JCDR, 9(3), ZE10.

26. Asawa, N., Bulbule, N., Kakade, D., \& Shah, R. (2015). Angulated implants: an alternative to bone augmentation and sinus lift procedure: systematic review. Journal of clinical and diagnostic research: JCDR, 9(3), ZE10. 